\title{
A Clinicopathological Profile of Sino- nasal Masses at a Tertiary Care Hospital: A Descriptive Study
}

\author{
https://doi.org/10.47210/bjohns.2021.v29i2.470
}

Nitin Deosthale, ${ }^{1}$ Priyal Patil, ${ }^{1}$ Sonali Khadakkar, ${ }^{1}$ Pavani Garikapati, ${ }^{1}$ Kanchan Dhote, ${ }^{1}$ Priti Dhoke, ${ }^{1}$ Vivek Harkare, ${ }^{1}$ Abhaysinh Deshmukh ${ }^{I}$

\begin{abstract}
$\underline{\text { Introduction }}$
The Sino-nasal mass is a common clinical entity. Although it has varied aetiology ranging from non-neoplastic to neoplastic, clinical presentation is overlapping that poses diagnostic dilemma. Objective of the study was to study the clinical profile of Sino-nasal masses in terms of demographic profile, clinical presentation and clinicopathological diagnosis.

Materials and Methods

A descriptive study was carried out at tertiary care hospital for 2 years. Clinically diagnosed cases of sino-nasal masses were included in the study. Previously treated cases, congenital lesions were excluded. Provisional diagnosis was made based on clinical and radiological evaluation. Diagnosis on histopathological examination was considered as definitive.

$\underline{\text { Results }}$

Total of 75 patients were included in the study. Demographic data showed slight male predominance (M:F=1.08:1), with most patients from age group 31-40 years (26.67\%). Nasal obstruction was the most common presenting symptom. The number of patients with non-neoplastic lesion was 48; 17 patients had neoplastic benign lesions while 6 patients had neoplastic malignant lesions.

\section{Conclusion}

Large number of patients presents with trivial symptoms but need careful examination and appropriate diagnosis. Inflammatory lesions outnumbered neoplastic lesions in our study. Clinical suspicion and appropriate investigations can guide in timely intervention and management of these patients reducing the morbidity and mortality in these patients.

$\underline{\text { Kevwords }}$
\end{abstract}

$\underline{\text { ABSTRACT }}$

Paranasal Sinuses; Nasal Obstruction; Nasal Polyps; Papilloma, Inverted; Carcinoma

$\mathrm{O}$ torhinolaryngologists encounter nasal masses very often in their routine Outpatient Department (OPD) practice. Hence it becomes essential to timely diagnose them and prevent any further untreatable complications. As easy as the nasal masses are encountered, diagnosing them is twice as challenging; one reason being its similarity in symptomology and late presentation.

The symptoms of sino-nasal masses encompass a wide range of symptoms like nasal obstruction, sneezing, epistaxis, disturbance in smell; orbital symptoms like epiphora, proptosis, swelling, diminution of vision; aural symptoms like earache, hard of hearing, snoring, apnoeic spells etc. ${ }^{1}$ Anatomically, the sino-nasal pathway being in close proximity to vital structures such as the eyes and the brain, it necessitates the need for its appropriate classification so as to treat it accordingly.

A thorough clinical examination is the primary requirement, which allows surgeon to judge the nature of lesion in terms of consistency, bleeding, attachments to surrounding structures, extent, tenderness, colour etc.

1 - Department of ENT, NKP Salve Institute of Medical Sciences and Research Centre and Lata Mangeshkar Hospital, Nagpur

Corresponding author:

Dr Sonali Khadakkar

email: ssonalikhadakkar@yahoo.com 
Radiological intervention like Computed Tomography (CT) of paranasal sinuses (PNS) provides the best visualization of nasal cavity and sinuses, anatomical variations. Along with the normal structural anatomy, it also guides us in classifying the lesion as benign or malignant as well as its origin, extent, and any bony involvement. In cases that are causing complications such as intra cranial extent is best analysed in CT-PNS. There was $90 \%$ correlation between nasal endoscopy and CT findings when combined than either of them used alone. ${ }^{2}$

The clinical features, Diagnostic Nasal Endoscopy, CT-PNS guide us in reaching to provisional diagnosis of the sino-nasal lesion. ${ }^{3}$ However, histopathological examination remains the gold standard for making the final diagnosis. Sino-nasal masses have vivid spectrum of histopathological types and grading of malignancies. So, it is of utmost importance to diagnose it accurately for proper management. Aim of this study was to study the clinical profile of Sino-nasal masses in terms of demographic profile, clinical presentation and clinicopathological diagnosis.

\section{Materials and Methods}

It was a descriptive study carried out at Tertiary Care Hospital of Central India for 2 years from October 2018 to October 2020 after approval from Institutional Ethics Committee. The inclusion criteria in the study were patients aged more than 10 years with clinical diagnosis of sino-nasal mass. Patients with congenital masses, recurrence of previously treated sino-nasal mass were excluded from the study. Formal written informed consent was obtained from all patients in the local dialect. According to the data found in ENT OPD in 2017, the number of patients with sino-nasal masses was about 100 . As per study of Chaudhary VK et al non neoplastic masses were $75 \%$ and neoplastic were $25 \%$. Based on this data the sample size was calculated using Open Epi info Version 7 as follows:

- $\quad$ Sample size $(n)=\left[\operatorname{DEFF}^{*} N p(1-p)\right] /[(d 2 / Z 21-$ $\mathrm{a} / 2 \mathrm{x}(\mathrm{N}-1)+\mathrm{p}(1-\mathrm{p})]$

- $\mathrm{DEFF}=1 \mathrm{Alpha}=0.05$ Beta=0.2 Z=1.96 N=100.

- Sample size for this study was 75 .
The various factors collected from the subjects included demographics along with socio-economic status according to Modified Kuppuswamy Classification5, chief complaints, past history and allergies. Patients were evaluated clinically using Diagnostic Nasal Endoscopy in all patients, Computer Tomography of Nose and Paranasal Sinuses whenever indicated. After surgical intervention, tissue was sent for histopathological examination to arrive at final diagnosis. All data was collected for statistical evaluation.

Statistical analysis was carried out by entering the data into Microsoft Excel spreadsheet. Analysis was done using Open Epi Info Version 7 Windows software program. Descriptive statistics included computation of percentages, means and standard deviations.

\section{Results}

A total of 75 patients were included in the study, where mean age of the study group was $36.92 \pm 13.96$ years. Majority of the patients were in the age group 30-40 years $(28 \%)$ and Male: Female ratio was 1.08:1 with $57.33 \%$ patients belonging to rural area.

Nasal obstruction was found to be the most common presenting complaint (97.33\%) followed by Nasal mass $(69.33 \%)$. Most of the sino-nasal masses were seen originating from middle meatus (54.66\%), followed by lateral wall (32\%). Majority of the study subjects had unilateral disease. $29(38.67 \%)$ cases had right sided sino-nasal mass followed by $27(36 \%)$ cases with left sided sino-nasal mass. Bilateral disease was seen in $19(25.33 \%)$ cases. (Table I)

Amongst the 75 patients, majority of patients i.e. $52(69.33 \%)$ had Non-neoplastic lesion of which 48 patients $(64 \%)$ had inflammatory lesions, 4(5.34\%) had granulomatous lesions. 17(22.67\%) had benign neoplastic lesions and 6(8\%) patients had malignant neoplastic lesions.

On Histopathological examination (HPE), 52 patients $(69.33 \%)$ had Non-neoplastic lesion, of which inflammatory polyps were most common seen in $50.67 \%$ cases followed by fungal sinusitis with polyp (9.33\%) and Rhinosporidiosis (4\%). Among 17 subjects having benign neoplastic lesions, Inverted 
Table I: Presenting Symptoms and Laterality of Sino-nasal masses in Study subjects $(n=75)$

\begin{tabular}{|c|c|c|c|}
\hline \multicolumn{2}{|c|}{ VARIABLES } & FREQUENCY (N) & PERCENTAGE (\%) \\
\hline \multirow{9}{*}{$\begin{array}{l}\text { Presenting } \\
\text { Symptoms* }\end{array}$} & Nasal Obstruction & 73 & 97.33 \\
\hline & Nasal Mass & 52 & 69.33 \\
\hline & Nasal Discharge & 57 & 76 \\
\hline & Reduced sense of Smell & 54 & 72 \\
\hline & Epistaxis & 27 & 36 \\
\hline & Facial swelling & 20 & 26.67 \\
\hline & Facial Pain & 23 & 30.67 \\
\hline & Ocular symptom & 15 & 20 \\
\hline & Post Nasal Drip & 37 & 49.33 \\
\hline \multirow{3}{*}{$\begin{array}{c}\text { Laterality of Sino- } \\
\text { nasal mass }\end{array}$} & Right & 29 & 38.67 \\
\hline & Left & 27 & 36 \\
\hline & Bilateral & 19 & 25.33 \\
\hline
\end{tabular}

*Multiple variables can occur

Papilloma (12\%) was the commonest lesion, followed by Juvenile Nasopharyngeal Angiofibroma (5.33\%) Among 6 patients having neoplastic malignant lesion, squamous cell carcinoma $(5.33 \%)$ was the commonest histopathological finding. (Table II)

Non neoplastic [14 out of $52(26.92 \%)$ ] and neoplastic benign lesions [6 out of $17(35.29 \%)$ ] were more common in the 4 th decade. Neoplastic Malignant lesions were common in the age 7 th decade onwards [3 out of $6(50 \%)]$. (Table III)

Males were predominantly affected by Neoplastic lesions (Both benign and malignant) while females had Non-neoplastic lesions $(55.77 \%)$ more as compared to males (44.23\%). Non-neoplastic (59.62\%) and malignant lesions $(83.33 \%)$ were more dominant in subjects from Rural area while Benign lesions (58.82\%) were more commonly found in Urban study population as compared to rural population (41.18\%). Non-neoplastic and Benign lesions commonly affected Lower middle, Upper-Lower and Lower class while Malignant lesions almost equally affected all classes. (Table IV)

\section{Discussion}

The sino-nasal tract and paranasal sinuses are although smaller regions anatomically, they hoard a complex variety of lesions ranging from non- neoplastic to neoplastic. The different kinds of elements such as epithelial, glandular, lymphoid, bone or cartilage are there in the nasal cavity and para nasal sinuses. Along with this, the tract is exposed to various infective agents, chemicals, antigens, mechanical factors. All these factors make sinonasal tract prone to give rise to a varied differential diagnosis of the masses. Detailed history, clinicopathological evaluation makes you reach to the provisional diagnosis. But for confirmation of the disease, Histopathological evaluation is a gold standard that guides you in the management and to know the prognosis.

In the present study, majority of study subjects belonged to 4 th and 5 th decade of life $(28 \%$ and $22.66 \%$ respectively) which was like the findings in studies by Vaghela K et al, ${ }^{6}$ Maheshwari A et $\mathrm{al}^{7}$ and 
Table II: Distribution of Sino-nasal masses in study subjects according to type of disease on histopathology Examination $(n=75)$

\begin{tabular}{|c|c|c|c|c|}
\hline \multicolumn{3}{|c|}{ TYPE OF DISEASE ON HISTOPATHOLOGY } & FREQUENCY & PERCENTAGE \\
\hline \multirow{5}{*}{$\begin{array}{c}\text { Non neoplastic } 52 \\
(69.33 \%)\end{array}$} & \multirow{3}{*}{$\begin{array}{l}\text { Inflammatory } \\
(\mathrm{N}=48,64 \%)\end{array}$} & Inflammatory Polyps & 38 & 50.67 \\
\hline & & Fungal sinusitis with polyp & 7 & 9.33 \\
\hline & & Rhinolith & 3 & 4 \\
\hline & \multirow{2}{*}{$\begin{array}{c}\text { Granulomatous } \\
(\mathrm{N}=4,5.33 \%)\end{array}$} & Rhinosporidiosis & 3 & 4 \\
\hline & & Rhinoscleroma & 1 & 1.33 \\
\hline \multirow{7}{*}{$\begin{array}{c}\text { Neoplastic } 23 \\
(30.67 \%)\end{array}$} & \multirow{4}{*}{$\begin{array}{c}\text { Benign }(N=17, \\
22.67 \%)\end{array}$} & Inverted Papilloma & 9 & 12 \\
\hline & & Capillary Haemangioma & 1 & 1.33 \\
\hline & & Nasopharyngeal Angiofibroma & 4 & 5.33 \\
\hline & & Nasolabial Cyst & 3 & 4 \\
\hline & \multirow{3}{*}{$\begin{array}{c}\text { Malignant }(\mathrm{N}=6, \\
8 \%)\end{array}$} & Chondroblastic Osteosarcoma & 1 & 1.33 \\
\hline & & Mucoepidermoid Carcinoma & 1 & 1.33 \\
\hline & & Squamous Cell Carcinoma & 4 & 5.33 \\
\hline \multicolumn{3}{|c|}{ Total } & 75 & 100 \\
\hline
\end{tabular}

Table III: Distribution of study subjects according to age and type of disease $(n=75)$

\begin{tabular}{|c|c|c|c|c|c|c|c|c|}
\hline \multirow{3}{*}{ AGE GROUP (IN YEARS) } & \multirow{2}{*}{\multicolumn{2}{|c|}{$\begin{array}{c}\text { NON NEOPLASTIC } \\
\text { Inflammatory and } \\
\text { Granulomatous }\end{array}$}} & \multicolumn{4}{|c|}{ NEOPLASTIC } & \multirow{2}{*}{\multicolumn{2}{|c|}{ TOTAL }} \\
\hline & & & \multicolumn{2}{|c|}{ Benign } & \multicolumn{2}{|c|}{ Malignant } & & \\
\hline & $(\mathbf{N})$ & $\%$ & $(\mathbf{N})$ & $\%$ & $(\mathbf{N})$ & $\%$ & $(\mathrm{~N})$ & $\%$ \\
\hline 11 to 20 & 8 & 15.38 & 4 & 23.53 & $\mathbf{0}$ & $\mathbf{0}$ & 12 & 16 \\
\hline 21 to 30 & 10 & 19.23 & 1 & 5.88 & $\mathbf{0}$ & $\mathbf{0}$ & 11 & 14.67 \\
\hline 31 to 40 & 14 & 26.92 & 6 & 35.29 & 1 & 16.67 & 21 & 28 \\
\hline 41 to 50 & 12 & 23.07 & 4 & 23.53 & 1 & 16.67 & 17 & 22.66 \\
\hline 51 to 60 & 6 & 11.54 & 1 & 5.88 & 1 & 16.67 & 8 & 10.67 \\
\hline$>60$ & 2 & 3.85 & 1 & 5.88 & 3 & 50 & 6 & 8 \\
\hline Total & 52 & 100 & 17 & 100 & 6 & 100 & 75 & 100 \\
\hline
\end{tabular}


Table IV. Distribution of study subjects according to Socio-demographic variables and type of diseases $(n=75)$

\begin{tabular}{|c|c|c|c|c|c|}
\hline \multirow{2}{*}{\multicolumn{2}{|c|}{ VARIABLES }} & \multicolumn{3}{|c|}{ TYPE OF DISEASE } & \multirow[b]{2}{*}{$\begin{array}{l}\text { TOTAL } \\
(\mathrm{N}=75)\end{array}$} \\
\hline & & $\begin{array}{c}\text { NON- } \\
\text { NEOPLASTIC } \\
(\mathbf{N}=\mathbf{5 2})\end{array}$ & $\begin{array}{c}\text { NEOPLASTIC } \\
\text { BENIGN }(\mathbf{N}=17)\end{array}$ & $\begin{array}{l}\text { NEOPLASTIC } \\
\text { MALIGNANT } \\
\quad(\mathbf{N}=6)\end{array}$ & \\
\hline \multirow{2}{*}{ Gender } & Male & $23(44.23 \%)$ & $12(70.59 \%)$ & $4(66.67 \%)$ & $39(52 \%)$ \\
\hline & Female & $29(55.77 \%)$ & $5(29.41 \%)$ & $2(33.33 \%)$ & $36(48 \%)$ \\
\hline \multirow{2}{*}{ Habitat } & Rural & $31(59.62 \%)$ & $7(41.18 \%)$ & $5(83.33 \%)$ & $43(57.33 \%)$ \\
\hline & Urban & $21(40.38 \%)$ & $10(58.82 \%)$ & $1(16.67 \%)$ & $32(42.67)$ \\
\hline \multirow{5}{*}{$\begin{array}{c}\text { Socio-economic } \\
\text { Status }\end{array}$} & Upper & $2(3.84 \%)$ & $1(5.88 \%)$ & $1(16.67 \%)$ & $4(5.33 \%)$ \\
\hline & Upper Middle & $5(9.62 \%)$ & $1(5.88 \%)$ & $1(16.67 \%)$ & $7(9.33 \%)$ \\
\hline & Lower Middle & $10(19.23 \%)$ & $6(35.29 \%)$ & $1(16.67 \%)$ & $17(22.67 \%)$ \\
\hline & Upper Lower & $20(38.46 \%)$ & $6(35.29 \%)$ & $1(16.67 \%)$ & $27(36 \%)$ \\
\hline & Lower & $15(28.85 \%)$ & $3(17.65 \%)$ & $2(33.33 \%)$ & $20(26.67)$ \\
\hline
\end{tabular}

Mane et al. ${ }^{8}$ While Zafar et $a l^{9}$ and Lathi et a ${ }^{10}$ studies observed prevalence of sino-nasal tumours more in 2nd to 4th decade. We found Non-neoplastic sinonasal masses predominantly in 3 rd to 5 th decade and neoplastic benign lesions in 4th decade while Neoplastic Malignant lesions were common in 7 th decade onwards. Our findings are consistent with Mane et $\mathrm{al}^{8}$ who found non-neoplastic lesion in 3rd to 5th decade with most commonly affected age group of 21-30 years $(30.5 \%)$ and Malignant tumours in 6th decade $(50 \%)$ and 7 th decade (33.33\%). Humayun et a ${ }^{11}$ reported majority of Non-neoplastic lesions in 3rd decade while Parajuli et al12 reported it in 2 nd and 3 rd decade.

In the present study, slight male predominance $(\mathrm{M}$ : $\mathrm{F}=1.08: 1)$ was observed in the study group. Male predominance has also been reported by Mane et $\mathrm{al}^{8}$ (1.3:1), Maheshwari et $\mathrm{al}^{7}(1.4: 1)$ and Lathi et $\mathrm{al}^{10}$ $(1.5: 1)$. In contrast to this, Bakari et $\mathrm{al}^{13}(1: 1.2)$ found female predominance in the study group. In our study non-neoplastic lesions were prevalent in females $(55.77 \%)$ while Benign (70.59\%) and malignant neoplastic lesions $(66.67 \%)$ were more common in males. According to Mane et $\mathrm{al}^{8}$ study, Non-neoplastic
(57.1\%) and Benign lesions (80\%) more predominant in males and malignant lesion (66.67\%) in females.

When type of residence was studied, most of the subjects were from rural area $(53.33 \%)$. Non-neoplastic lesions (Inflammatory, granulomatous) and malignant lesions were more common in rural population as compared to the urban, while benign lesions were more common in people residing in urban area. Dutta et al ${ }^{14}$ $(69.70 \%)$ and Pandey et $\mathrm{al}^{15}(60 \%)$ had similar findings of majority of cases belonging to rural area. Majority of patients belonged to upper lower class (36\%) when socioeconomic status was considered which was similar to the studies from Lathi et $\mathrm{al}^{9}$ and Bist et all. ${ }^{5}$

Nasal obstruction (97.33\%) followed by nasal discharge $(76 \%)$ were the most common presenting complaints in our study subjects. Maheshwari et $\mathrm{al}^{7}$ also found nasal obstruction in $88.75 \%$ and nasal discharge in $72.5 \%$ patients as common clinical presentation. Humayun et $\mathrm{al}^{11}$ found nasal obstruction $(100 \%)$ in all patients of sino-nasal mass. Our findings are also consistent with the studies done by Lathi et $\mathrm{al},{ }^{10} \mathrm{Bist}$ et al. ${ }^{16}$ In our study, most of the cases were unilateral $(74.67 \%)$ with majority of patients having right sided 
tumour (38.67\%). According to Maheshwari et $\mathrm{al}^{7}$ study, majority of the Sino-nasal masses were unilateral $(56.25 \%)$. Similar was the finding observed by Bakri et $\mathrm{al}^{13}(55.3 \%)$ and Bist et $\mathrm{al}^{16}(74.55 \%)$. In contrast, Lathi et $\mathrm{al}^{10}$ reported a high incidence of bilateral sinonasal mass $(51.8 \%)$ so also by Zafar et $\mathrm{al}^{9}(60 \%)$. This difference might be due to geographical variation.

On Histopathological evaluation, it was observed that majority were Non neoplastic masses $(69.33 \%)$ as compared to Neoplastic lesions seen in $30.67 \%$ cases (Benign in $22.67 \%$ and Malignant in $8 \%$ ). These findings are consistent with the study by Mane et $\mathrm{al}^{8}$ who found non-neoplastic lesions in 83.33\%, Neoplastic Benign lesions in $11.8 \%$ and malignant lesions in $5.5 \%$ cases of Sino-nasal masses. Parajuli et al ${ }^{12}$ reported $80.4 \%$ non-neoplastic lesions, 12.8 benign neoplastic and $6.8 \%$ malignant lesions. Kulkarni et a $1{ }^{17}$ found Non-neoplastic lesions in $86.3 \%$ cases, benign lesions in $11.1 \%$ cases and malignant lesions in $2.6 \%$ cases. Similar was the findings in the studies by Zafar et al9 and Lathi et al. ${ }^{10}$

\section{Conclusion}

Sino-nasal masses presented with trivial symptoms such as nasal obstruction or nasal discharge, but with wide spectrum of differential diagnosis. Inflammatory lesions outnumbered neoplastic lesions in our study. Non-neoplastic and Benign lesions were predominantly seen in middle age patients while malignant lesions in old aged. The findings must be interpreted in the light of high clinical suspicion, and complete ENT examination including, endoscopic, radiologic studies but histopathological study remains the mainstay in final diagnosis. Treatment is always individualized according to the indication in every patient.

\section{References}

1. Somani S, Kamble P,Khadkears S. Mischievous presentation of nasal masses in rural areas. Asian Journal of Ear Nose Throat.2004; 2:9-17

2. Johansson L, Ākerlund AM Melen I, Holmberg K, Bende M. Prevalence of nasal polyps in adults: the Skovde populationbased study. Annals of Otology, Rhinology \& Laryngology 2003;112(7):625-9
3. Drake-lee A. Physiology of the nose and paranasal sinuses, In: Browning GG, Merchant SN, Kelly G (eds). Scott-Brown's Otolaryngology. Head and Neck Surgery: 7th ed. Great Britain: Hodder Arnold. 2008; 2:1355-7

4. Chaudhary VK, Tailor MK, Kotia A, Aseri Y, Verma PC. Clinico-Pathological Study and Endoscopic Management of Sino-Nasal Masses. IOSR Journal of Dental and Medical Sciences 2017; 16(10):16-9

5. Saleem SM. Modified Kuppuswamy socioeconomic scale updated for the year 2020. Indian Journal of Forensic and Community Medicine 2020;7(1):1-3

6. Vaghela K, Shah B. Evaluation of paranasal sinus diseases and its histopathological correlation with computed tomography. Journal of Oral Medicine, Oral Surgery, Oral Pathology and Oral Radiology $2018 ; 4(1): 11-3$

7. Maheshwari A, Bansal A. Clinico-pathological spectrum of sinonasal masses: a tertiary care hospital experience. International Journal of Otorhinolaryngology and Head and Neck Surgery 2017; 3(4):1015-9

8. Mane PS, Agale SV. Clinicopathological Study of Sinonasal masses. Annals Pathol Laboratory Med. 2017; 4(3):261-7

9. Zafar U, Khan N, Afroz N, Hasan SA. Clinicopathological study of non-neoplastic lesions of nasal cavity and paranasal sinuses. Indian Journal of Pathology and Microbiology 2008; 51(1):26-9

10. Lathi A, Syed MM, Kalakoti P, Qutub D, Kishve SP. Clinicopathological profile of sinonasal masses: a study from a tertiary care hospital of India. Acta Otorhinolaryngologica Italica 2011; 31(6):372-7

11. Humayun AHM, Zahurul Huq AHM, Ahemad SMT, Kamal MS Bhattacharjee N. Clinicopathological study of sinonasal masses. Bangladesh Journal of Otorhinolaryngology 2010;16(1):15-22

12. Parajuli S, Taladhar A. Histopathological spectrum of masses of the nasal cavity, paranasal sinuses and nasopharynx. Journal of Pathology of Nepal 2013; 3:351-5

13. Bakari A, Afolabi OA, Adoga AA, Kodiya AM, Ahmad BM. Clinico-pathological profile of sinonasal masses: an experience in national ear care center Kaduna, Nigeria. BMC Research Notes 2010 (1):1-5

14. Dutta M, Ghatak S, Sen I, Sinha R. Variable Presentations of Sinonasal Polypoid Masses: A Tertiary Institution Experience. Kathmandu Uni Med J. 2016;14(56):322-7

15. Pandey RK, Kumar D, Shrivastava N, Kumar N. Clinicoepidemiological evaluation of patients with sinonasal masses attending a tertiary care hospital in Jharkhand: a three- year retrospective study. International Journal of Otorhinolaryngology and Head and Neck Surgery 2017; 3(1):132-4

16. Bist SS, Varshney S, Baunthiyal V, Bhagat S, Kusum A. Clinico-pathological profile of sinonasal masses: An experience in tertiary care hospital of Uttarakhand. National Journal of Maxillofacial Surgery 2012;3(2):180-6 
17. Kulkarni AM, Mudholkar VG, Acharya AS, Ramteke RV. Histopathological study of lesions of nose and paranasal sinuses. Indian J Otolaryngol Head Neck Surg. 2012; 64(3):275-9. 